\title{
Electron tomography of fiber cell cytoplasm and dense cores of multilamellar bodies from human age-related nuclear cataracts
}

\author{
M. Joseph Costello ${ }^{a,}{ }^{,}$, Alain Burette ${ }^{a}$, Mariko Webera, Sangeetha Metlapallya ${ }^{a}$ Kurt 0. \\ Gilliland $^{\mathrm{a}}$, W. Craig Fowler ${ }^{\mathrm{b}}$, Ashik Mohamed ${ }^{\mathrm{C}}$, and Sönke Johnsen ${ }^{\mathrm{d}}$ \\ aDepartment of Cell and Developmental Biology, CB 7090, University of North Carolina, Chapel \\ Hill, NC 27599, USA \\ ${ }^{b}$ Department of Ophthalmology, University of North Carolina, Chapel Hill, NC, USA \\ cProf. Brien Holden Eye Research Centre, L V Prasad Eye Institute, Hyderabad, India \\ dDepartment of Biology, Duke University, Durham, NC, USA
}

\begin{abstract}
Human nuclear cataract formation is a multi-factorial disease with contributions to light scattering from many cellular sources that change their scattering properties over decades. The aging process produces aggregation of cytoplasmic crystallin proteins, which alters the protein packing and texture of the cytoplasm. Previous studies of the cytoplasmic texture quantified increases in density fluctuations in protein packing and theoretically predicted the corresponding scattering. Multilamellar bodies (MLBs) are large particles with a core of crystallin cytoplasm that have been suggested to be major sources of scattering in human nuclei. The core has been shown to condense over time such that the refractive index increases compared to the adjacent aged and textured cytoplasm. Electron tomography is used here to visualize the 3D arrangement of protein aggregates in aged and cataractous lens nuclear cytoplasm compared to the dense protein packing in the cores of MLBs. Thin sections, $70 \mathrm{~nm}$ thick, were prepared from epoxy-embedded human transparent donor lenses and nuclear cataracts. Tilt series were collected on an FEI T20 transmission electron microscope (TEM) operated at $200 \mathrm{kV}$ using $15 \mathrm{~nm}$ gold particles as fiducial markers. Images were aligned and corrected with FEI software and reconstructed with IMOD and other software packages to produce animated tilt series and stereo anaglyphs. The 3D views of protein density showed the relatively uniform packing of proteins in aged transparent lens nuclear cytoplasm and less dense packing of aged cataractous cytoplasm where many low-density regions can be appreciated in the absence of the TEM projection artifacts. In contrast the cores of the MLBs showed a dense packing of protein with minimal density fluctuations. These observations support the conclusion that, during the nuclear cataract formation, alterations in protein packing are extensive and can result in pronounced density fluctuations. Aging causes the MLB cores to become increasingly different in their protein packing from the adjacent cytoplasm. These results support the hypothesis that the MLBs increase their scattering with age and nuclear cataract formation.
\end{abstract}

\author{
(C) 2012 Elsevier Ltd. All rights reserved. \\ *Corresponding author. Tel.: +1 919966 6981; fax: +1 919966 1856. mjc@ @med.unc.edu (M.J. Costello). \\ Conflicts of interest \\ None. \\ Financial disclosures \\ None.
}




\section{Keywords}

age-related nuclear cataract; electron tomography; protein density fluctuations; multilamellar bodies; high molecular weight aggregates

\section{Introduction}

Human nuclear cataract formation is an age-related disease possibly influenced by many environmental, metabolic and genetic factors that produce increased diffuse light scattering followed, in later stages, by complete opacification in the central region of the lens (Costello and Kuszak, 2008; Graw, 2009; Michael and Bron, 2011; Zhou et al., 2011). The entire mass of the lens nucleus is filled with mature fiber cells consisting of a plasma membrane enclosing a cytoplasm composed mainly of condensed specific crystallin proteins. From a cell biology viewpoint, the most probable sources of scattering in human age-related nuclear cataracts include aggregation of cytoplasmic proteins (Benedek, 1997; Metlapally et al., 2008), damage to membranes producing cellular debris (Al-Ghoul et al., 1996; Costello et al., 2008; Vrensen and Willekens, 1989), and large particles, called multilamellar bodies (MLBs), containing a core of cytoplasmic proteins and a lipid-rich membrane coat (Costello et al., 2007; Gilliland et al., 2001, 2004, 2008). Modified cellular structures in the lens change with time, leading to a gradual increase in opacity and an overall diminished contrast at the retina due to absorption and scattering of incident light. Many of the ultrastructural alterations can be visualized with thin-section transmission electron microscopy (TEM), although technical limitations, due to artifacts of projecting structural features onto the image plane, have put serious constraints on the information available from morphological studies. To overcome some of these limitations, we have used electron tomography (Frey et al., 2006; Schietroma et al., 2009), a valuable tool that helps visualize the 3D arrangement of lens fiber cell proteins in the cytoplasm and particle cores. The advantages offered by tomography include improvement in image quality by potentially minimizing image degradation caused by the superimposition of mass within a thin section. The orientation and thickness of a slice within a 3D reconstruction can be selected to optimize the visualization of specific details. The improvement is analogous to that obtained when out-of-focus light is removed using confocal, multiphoton or deconvolution light microscopy, where the objects are more clearly seen in optical slices even though the technical and software enhancements have not altered the resolution of the images. The preliminary images presented here provide new insights about how protein redistribution during aging contributes to the formation of high molecular weight (HMW) protein aggregates that produce excessive light scattering from human lens nuclei.

\section{Materials and methods}

\subsection{Lenses}

Age-related cataractous lens nuclei were obtained after extra capsular surgical extraction as described earlier (Gilliland et al., 2004; Metlapally et al., 2008). From the US, eight nuclei 56-85 years old were obtained with grades 1-3, and from India, 10 nuclei 38-75 years old were obtained with grades 3-4, on a 0-4 nuclear cataract scale (Chylack et al., 1983). The Indian nuclei were advanced nuclear cataracts from patients who were functionally blind at the time of cataract surgery. Transparent donor lenses ranged in age from 34 to 71 years for 8 lenses from the US and 48-78 years for 5 lenses from India. Representative images of transparent donor lens with typical pale yellow nuclei have been published previously (AlGhoul et al., 1996; Chylack et al., 1983; Taylor et al., 1996) and many images of age-related nuclear cataracts of the type examined here have been reported (Al-Ghoul et al., 1996; Chylack et al., 1983; Costello and Kuszak, 2008). An example of an extracted nucleus 
representative of the advanced cataracts from India was published previously (Costello et al., 2008). All lenses were obtained following procedures reviewed by the Institutional Review Board for protection of human subjects according to the tenets of the Declaration of Helsinki.

\subsection{Sample preparation and transmission electron microscopy}

Vibratome sections approximately $200 \mu \mathrm{m}$ thick were cut from fresh lenses and processed as described previously (Gilliland et al., 2004). Briefly, Vibratome sections were immersion fixed for $12-18 \mathrm{~h}$ in $2.5 \%$ glutaraldehyde, $2 \%$ paraformaldehyde and $1 \%$ tannic acid in 0.1 $\mathrm{M}$ cacodylate buffer ( $\mathrm{pH}$ 7.2). Fixed sections were washed with $0.1 \mathrm{M}$ cacodylate for three 15 -min washings, treated with cold $0.5 \%$ osmium tetroxide for $60 \mathrm{~min}$, washed with deionized distilled water for three 15-min washings, washed once with $50 \%$ ethanol for 5 min, stained in $2 \%$ uranyl acetate (in 50\% ethanol) in the dark for $30 \mathrm{~min}$ and dehydrated through a graded ethanol series. Sections were infiltrated and embedded in an epoxy resin (Epon 812, EMS, Hatfield, PA). Thin sections $(70 \mathrm{~nm}$ ) were cut with a diamond knife (Diatome US, Hatfield, PA) from mesas raised to include the embryonic and fetal nuclei. Sections on copper grids (300 mesh hexagonal) were stained with uranyl acetate and lead citrate.

\subsection{Electron tomography}

For tomographic analysis, $15 \mathrm{~nm}$ colloidal gold particles were deposited on one side to serve as fiducial markers. Thin sections selected for analysis were irradiated in a spread electron beam before initiating a tilt series to limit anisotropic specimen thinning during image collection. Single-tilt series (Model 2020, Fischione Instruments, Export, PA) were collected at 11,500- and 29,000-fold magnifications (corresponding to a pixel size of 1.95 and 0.78 $\mathrm{nm}$, respectively) using an FEI Tecnai $\mathrm{G}^{2}$ Twin operated at $200 \mathrm{kV}$ coupled to a $2048 \times$ 2048 FEI Eagle CCD camera (at the Shared Materials Instrumentation Facility, SMiF, Duke University). The FEI tomography acquisition software package was used to acquire tilt series, from $-65^{\circ}$ to $+65^{\circ}$, in $2^{\circ}$ increments. The IMOD software package (Kremer et al., 1996) was used for the entire procedure of image alignment and reconstruction. The Amira software package (Version 5.3.2; Mercury Computer Systems, San Diego, CA, USA) was used for the three-dimensional analysis and visualization.

\section{Results}

\subsection{Comparison of lens nuclear cytoplasm from an Indian transparent donor lens and an opaque nucleus from an advanced cataract}

The texture of nuclear fiber cell cytoplasm is a measure of the extent of post-translational modifications, cross-linking and aggregation of crystallins during aging and cataract formation. Representative electron micrographs (Fig. 1A, D) and selected images from tomographic reconstructions (Fig. 1B, C, E, F) demonstrate differences in the fiber cell cytoplasmic texturing of a human transparent lens (Indian donor, 56 years, A-C) and an advanced nuclear cataract (Indian, 48 years, D-F). The transparent lens cytoplasmic protein packing is relatively homogeneous and dense, showing uniform texturing, whereas the packing in the nuclear cataract is heterogeneous with irregular high- and low-density regions (Fig. 1E, arrowheads and arrows, respectively). The cataractous sample shows marked density fluctuations that partially account for the nuclear opacity based on a quantitative analysis (Metlapally et al., 2008). Several $15 \mathrm{~nm}$ gold particles, appearing in the 2D micrographs as dark circular structures and as light spots in the inverse contrast reconstructions, serve as an internal size calibration as well as fiducial markers. The gold particle size was chosen to match closely the measured average size of the spherical 
assemblies of alpha-crystallin monomers (Haley et al., 2000, 1998), the most abundant protein in the fiber cell cytoplasm.

Careful examination of selected images from a 3D reconstruction shows that the nuclear cytoplasm from a donor lens is composed of closely packed small globular units uniformly distributed with little variation in the distribution through the depth of the section. The structural subunits are similar in average size to the gold particles (10-20 nm) as is most evident in the video of step-wise animated rotations (Fig. 2 video). Corresponding cytoplasm from a nuclear cataract shows clumping of protein into irregular aggregates of higher density (brighter regions in reconstructions) and lower density (irregular dark) regions between the aggregates. These fluctuations are more evident at selected tilts in the video of the reconstruction (Fig. 3 video). The result is a markedly increased variability in protein density that results in pronounced fluctuations in refractive index. As suggested previously, such a pattern of protein texture could account for the excessive light scattering leading to nuclear opacity in this advanced Indian cataract (Metlapally et al., 2008).

The resolution of the reconstructions is similar to the 2D electron micrographs based on the visualization of plasma membrane (Fig. 4). The stained halves of the membrane bilayer in a typical electron micrograph (Fig. 4A, inset arrows) are visible as two dark lines separated by a light central band representing the stain-excluding hydrophobic layer. The overall thickness is about $7 \mathrm{~nm}$ based on high-magnification TEM images (Costello et al., 1989, 2008; Gilliland et al., 2001). Exactly the same region and membrane are visible in the 3D reconstruction when a thin slice is imaged at the proper orientation so that the membrane is viewed edge-on (Fig. 4B, inset arrows), revealing the distinctive single bilayer membrane with the same curvature and overall thickness along its length. Because both halves of the bilayer are visible, it is reasonable to estimate the resolution of the images and reconstructions at about 3-4 nm, similar to the estimates given in other tomography studies of thin sections (Burette et al., 2012; Schietroma et al., 2009). These images also illustrate some important advantages of tomographic reconstruction. The 2D TEM image inset (Fig. $4 \mathrm{~A}$, inset) shows mass within the $70 \mathrm{~nm}$ section obscuring the membrane and the adjacent extracellular space (because the tilt angle is not optimal) and in the reconstruction using a thinner slice (about $40 \mathrm{~nm}$ ) the membrane is seen to have two protein-like deposits on the concave surface of the membrane extending into the extracellular space (Fig. 4B, inset, second and third arrows from bottom) consistent with previous images of membranes (Costello et al., 2008). Because the membrane's natural curvature is preserved along its length, the inset (Fig. 4B) also suggests that the single-tilt reconstruction has produced good resolution in all directions.

Further comparisons of the reconstructions from transparent donor lenses and nuclear cataracts demonstrate the importance of selecting the proper 3D view. Representative slices through the 3D reconstructions show the texture and homogeneity of the protein mass distribution (Fig. 5A and D). These views are consistent with and analogous to standard TEM images (Fig. 1A and D). The donor lens cytoplasm in a thin slice of the reconstruction is relatively smooth and homogeneous whereas the cataract cytoplasm shows variations in density. At one location (Fig. 5A and D, boxed) stepping through the reconstruction shows that there is very little change for the donor lens (Fig. $\left.5 \mathrm{~B}_{1}-\mathrm{B}_{3}\right)$ but significant $3 \mathrm{D}$ density variations for the cataract (Fig. $5 \mathrm{E}_{1}-\mathrm{E}_{3}$ ), perhaps indicative of the large-scale ultrastructural changes that occur during cataract formation. This is much easier to visualize at higher magnification of the selected regions (Fig. 5C and F) and in stereo anaglyph videos of the reconstructions (Figs. 6 and 7 videos). Even in projections of several slices through the reconstructions adjusted at the same threshold levels in reverse contrast, the density of protein packing in the donor cytoplasm is relatively uniform (Figs. 5C and 6) compared to the wide variations in density of the cataract (Figs. 5F and 7). The clumping of protein into 
large aggregates separated by low-density regions gives the cataract a characteristic pattern of density fluctuations. The scale of the fluctuations is illustrated by the 16-nm diameter circle placed over a high-density region (Fig. $5 \mathrm{~F}$ ), although it is clear that none of the globular patterns presents a circular profile as native alpha-crystallins would (Peschek et al., 2009) and adjacent low-density regions are very irregular in size and shape. The highdensity regions could be visualizations of age-related HMW protein aggregates that contribute to the excessive scattering and nuclear opacification of this lens.

\subsection{Electron tomography of multilamellar bodies in early stage nuclear cataracts}

The cytoplasm in early stage nuclear cataracts is only slightly more textured than the transparent donor control (Fig. 8, US age 85 , grade 2 on $0-4$ scale). This minor cytoplasmic texturing is also similar to 7 out of 10 advanced cataracts from India and corresponds to predicted scattering of about $10 \%$ or less (Metlapally et al., 2008). Thus, cytoplasmic texture during aging and at the beginning of nuclear cataract formation contributes in a minor way to nuclear light scattering. Other contributions to nuclear scattering need to be considered for the development of nuclear cataracts. Multi-lamellar bodies (MLBs) have been observed in all nuclear cataracts examined from the US and India (Gilliland et al., 2004, 2008). MLBs in standard 2D electron micrographs (Fig. 8A and C) display an overall circular or elliptical profile and a central core of uniform staining density. The low-density regions surrounding the cores probably originally contained the multiple lipid bilayers that characterized the MLBs as distinct structures when they were formed (Costello et al., 2010). As a result of aging and post-translational modification including lipid breakdown, the regions around the cores may have lost all the lipid-rich membranes as the low-density rims have enlarged in size. This probably represents the most advanced state of the MLBs observed (Costello et al., 2010). An important observation is that the texturing of the cytoplasm and the MLB cores are similar (with fluctuations in density less than $50 \mathrm{~nm}$ ) and emphasizes the large fluctuations (on a micron scale) in protein density across the MLBs (Fig. 8). Over a range of magnifications, the cytoplasm within the cores (Fig. 4B and D, central boxed regions) appears to be similar to or slightly smoother than the surrounding cytoplasm (Fig. 8B and D, outer boxed regions). The appearance of these MLBs suggests that, as the cores age, they appear to have condensed, leaving large clear low-density rims. Thus, the high density and fine texture of some cores (Fig. 8D) are consistent with the measured high refractive index and predicted increased light scattering (Costello et al., 2010). The textures of the surrounding cytoplasm and MLB cores are readily compared in videos of the 3D reconstructions (Figs. 9 and 10 videos).

\section{Discussion}

Electron tomographic reconstructions of standard thin sections were employed to extend the ultrastructural analysis of the texture of nuclear fiber cell cytoplasm from transparent donor and cataractous lenses. The cytoplasmic texture is a direct indication of the extent of posttranslational modification of crystallin proteins and their aggregation during aging and cataract formation. Previous examination of $2 \mathrm{D}$ electron micrographs using quantitative Fourier image analysis demonstrated slight texturing of aged transparent lenses and early stage nuclear cataracts (Freel et al., 2002; Taylor and Costello, 1999). However, it was difficult to determine the extent of texturing by direct examination of the $2 \mathrm{D}$ images because the projection artifact compresses all the structural information into flat images. Electron tomography is used here to explore the true $3 \mathrm{D}$ distribution of protein density throughout the thin sections. The most important comparison was between a 56-year-old Indian donor lens to a totally opaque nuclear cataract from a 48 -year-old Indian patient. The low magnification views (Fig. 1) and 3D reconstructions (Figs. 2 and 3 and video supplements) clearly showed major differences in texture that were emphasized at high magnification (Fig. 5) and especially in animated stereo views (Figs. 6 and 7 and video supplements). The protein mass 
in the transparent donor nucleus filled the 3D thin section nearly uniformly, whereas the cataract showed marked variations in density sufficient to create pronounced fluctuations in refractive index. At the edges of low-density regions, small globular particles were seen clustered to form larger dense objects that may be the first microscopic views of HMW protein aggregates. The similar ages of the compared nuclei suggest that the differences in texture are most likely due to cataract formation.

An important concern is how the observed cytoplasmic textures contribute to the predicted light scattering from the nuclei. Images derived from the tomograms suggest that the transparent donor lens displays minor density fluctuations with dimensions less than $50 \mathrm{~nm}$ whereas the cataract shows large particle clusters and variations in density in the range 50$200 \mathrm{~nm}$. These rough estimations cannot be determined accurately because the particle clusters and low-density regions between clusters are highly irregular in size and shape. Such distributions are appropriately analyzed employing the Debye-Bueche theory for inhomogeneous materials, as performed on lens nuclear cytoplasm including the Indian lenses examined here (Metlapally et al., 2008). The quantitative analysis was based on the observation that heavy metal en bloc stains generally bind to proteins non-specifically, that protein density is related to optical density in electron micrographs and that protein density is directly proportional to refractive index regardless of the molecular identity. The optical density variations in electron micrographs were converted to fluctuations in refractive index as inputs to the Debye-Bueche formulae for light scattering as a function of angle and wavelength (Metlapally et al., 2008). Relevant to the present study, the Debye-Bueche analysis predicted the low amount of light scattering for the Indian donor lens at less than $2 \%$ for $400 \mathrm{~nm}$ incident light (see Fig. 3, black line in Metlapally et al., 2008) and for the Indian advanced cataract the predicted scattering was $34 \%$ for $400 \mathrm{~nm}$ incident light (see Fig. 3, yellow line in Metlapally et al., 2008). Thus, the observed textures in the Indian lenses can be directly related to predicted light scattering and the density fluctuations in the Indian cataract are sufficient to render the nucleus opaque.

Tomography was performed on MLBs from typical age-related nuclear cataracts from the US (Fig. 8). The MLBs examined were selected as representative of advanced stage MLBs found in all nuclear cataracts including those from India (Gilliland et al., 2008) and are characterized by roughly $2-\mu \mathrm{m}$ oval shapes in sections (ellipsoidal in 3D), a condensed core and a wide low-density rim around the core (Costello et al., 2010). The cytoplasm and membranes adjacent to the MLBs are typical of cells in the fetal and embryonic nuclei of human lenses. The 3D reconstructions show that the cytoplasm has become textured during the aging process (Fig. 8), qualitatively slightly more textured than the cytoplasm from the Indian donor lens but significantly less textured compared to the Indian cataract (Figs. 1-3). The predicted scattering from nuclei with cytoplasmic texturing similar to that seen around the MLBs displayed here is estimated to be less than $10 \%$ of the incident light (Metlapally et al., 2008). The important observation for these MLBs is that the cores display similar texturing to the surrounding cytoplasm, suggesting that the protein in the MLB cores is at least as condensed. New quantitative methods have been employed to predict the refractive index of MLB cores from the standard TEM electron micrographs: The calculated refractive indices for the MLB cores were 1.46 (Fig. 8A) and 1.48 (Fig. 8C), compared to an assumed index of the cytoplasm of 1.42 (Costello et al., 2010). The Mie theory of light scattering predicts that the total scattering from nuclei containing such MLBs would be in excess of $30 \%$ (Costello et al., 2010). Based on an analysis of the angular dependence of Mie scattering (Costello et al., 2007, 2010), light scattering from textured cytoplasm has a major component at high angles (contributing to retinal stray light), whereas scattering from the MLBs is predicted to occur preferentially in the forward direction, mainly within $15^{\circ}$ of the optic axis, thus potentially having a major effect on image formation at the fovea. 
All of the reconstructions indicate that the cytoplasm is composed mainly of globular objects that are closely packed and similar in size, roughly in the range of 10-20 nm. This size range for structural components is similar to that of alpha-crystallin oligomeric assemblies, which are spherical hollow-core particles with a protein shell and a hydrophobic interior typical of small heat shock protein (sHsp) complexes and consistent with their role as molecular chaperones (Horwitz, 1992, 2003, 2009). The alpha-crystallins have been shown to be heteromeric and variable in size, ranging from about 12 to $18 \mathrm{~nm}$ with an average size of about $16 \mathrm{~nm}$, based on cryo-EM imaging and reconstructions at about $4 \mathrm{~nm}$ resolution (Haley et al., 1998, 2000). Recent hydrodynamic and negative stain TEM analysis confirmed the spherical shape in reconstructed recombinant alphaB-crystallin particles at $13.5 \mathrm{~nm}$ diameter (molecular mass of $475 \mathrm{kDa}, 24$ subunits) with $2 \mathrm{~nm}$ resolution (Peschek et al., 2009). A range of sizes for isolated native bovine alpha-crystallin, up to $20 \mathrm{~nm}$ diameter (molecular mass in excess of $600 \mathrm{kDa}, 32$ subunits), have been reported (Peschek et al., 2009) and early TEM studies reported sizes slightly smaller than $10 \mathrm{~nm}$ (Koretz and Augusteyn, 1988). Because of the distinctive spherical shape and high concentration of alpha-crystallin, it was expected that the particles would be readily recognizable in intact cytoplasm. However, this does not appear to be the case, even for young rat lens cortical cytoplasm that was analyzed by conical tomography in which the high density of protein obscured the underlying fine structure of the cytoplasmic components (Schietroma et al., 2009; Zampighi et al., 2011). Furthermore, the aging of the lens induces numerous modifications to alpha-crystallin based on recent proteomics analyses (Asomugha et al., 2010; Grey and Schey, 2009; Sharma and Santhoshkumar, 2009; Su et al., 2011). These modifications include deamidations, oxidations and acetylations, as well as truncations and phosphorylations that could affect sHsp particle assembly and chaperone function. An important observation for human lenses is that almost no native alpha-crystallin was detected in the nuclear region of aged lenses by MALDI imaging mass spectrometry (Grey and Schey, 2009). The modifications to alpha-crystallin also include extensive chaperone interactions with partially unfolded target proteins, especially beta-and gamma-crystallins, both of which also show extensive post-translational modifications (Asomugha et al., 2010; Lampi et al., 1998; Su et al., 2011). At the resolution available in the reconstructions, it does not appear that any of the crystallin molecular components or complexes can be uniquely identified.

Great interest has been generated in HMW protein aggregates as possible sources of excess light scattering in human age-related nuclear cataracts (Benedek, 1971; Jedziniak et al., 1973, 1975; Spector et al., 1974). When originally described and detected by dynamic light scattering, these aggregates were estimated to be between 50 and 150 million daltons, which would represent globular particles with equivalent diameters of about $50 \mathrm{~nm}-70 \mathrm{~nm}$, based on a typical protein density of $1.37 \mathrm{~g} / \mathrm{cm}^{3}$ (Erickson, 2009). The irregular aggregates visible in the Indian cataract at high magnification (Figs. 5F and 7) are close to this size, as are the fluctuations in density in this region. To our knowledge, no other microscopic visualization of HMW aggregates or their distribution has been reported from intact human lenses or nuclear cataracts. Aggregations of alpha-crystallin in a fraction showing extensive selfassociation isolated from transparent bovine nuclei show HMW aggregates 100-500 nm in diameter (Kramps et al., 1975). Irregular particle aggregates were described in the urea insoluble membrane fraction from a nucleus of an age-related nuclear cataract (Costello and Kuszak, 2008). The prominent feature of these potential HMW aggregates was the association of nearly spherical 14-16 nm diameter particles in linear and branched arrays that contained at least 20-40 particles and could be enclosed within a diameter of $100 \mathrm{~nm}$. The aggregates could be linked by self-association of alpha-crystallin or the core of the aggregates could be composed of partially degraded beta- and gamma-crystallins bound to chaperone forms of alpha-crystallin (Rao et al., 1995). Another possibility is that the particles could be linked to beaded filament proteins or their fragments (FitzGerald, 2009; 
Sandilands et al., 1995; Wang et al., 2010). In recent conical tomography studies of rat lens deep cortical cytoplasm, intermediate beaded filaments in unique kinked patterns or underlying alpha-crystallin assemblies were emphasized (Schietroma et al., 2009; Zampighi et al., 2011). No such filaments or assemblies were observed in the reconstructions presented here from aged human nuclei. However, intermediate filaments could still contribute to the formation of HMW aggregates. Maturation and fragmentation of beaded filament proteins occurs during the final stages of differentiation and aging (FitzGerald, 2009) and recently proteomics was used to show that intact filensin and phakinin beaded filament proteins are contained in the HMW aggregates in aged donor and cataractous nuclei (Su et al., 2011).

Electron tomography has potential for uncovering the complex crystallin interactions in fiber cell cytoplasm that occur during aging and cataract formation. The resolution of 3-4 nm available in this and other tomography studies of conventional thin sections (Burette et al., 2012; Frey et al., 2006; Schietroma et al., 2009; Zampighi et al., 2006), does not allow unique identification of specific crystallins and their modified forms. Technical improvements, such as multiple tilt axes, higher tilt angles to reduce the missing cone of information, and higher accelerating voltages, may provide improved resolution at the level of individual molecules. Further improvements may be possible with new methods for vitrification, such as, high pressure freezing shown to preserve thick sections from adult human lens nuclei (Costello, 2006). Vitrified thick sections could be processed by freeze substitution, which preserves more of the cytoplasmic components, followed by tomography of thin sections at room temperature (Sosinsky et al., 2008) or could be cryo-sectioned followed by examination of frozen hydrated thin sections at low temperature (Vanhecke et al., 2011). Both approaches will be technically demanding and will provide complementary methods of contrasting crystallin proteins in native configurations after they are formed in young lenses compared to aggregated forms in aged cataractous lenses.

\section{Conclusions}

Electron tomography has been used to emphasize the distinctive differences in the uniform packing of cytoplasmic proteins in transparent donor lenses compared to the heterogenous distribution of protein in some advanced cataracts. Potential HMW protein aggregates are visible in reconstructions of advanced nuclear cataracts. The fine texture of proteins reported here for the cores of large globular MLBs is consistent with very densely packed protein and high refractive index, as well as pronounced fluctuations in refractive index across the MLBs that are predicted to produce strong light scattering.

\section{Supplementary Material}

Refer to Web version on PubMed Central for supplementary material.

\section{Acknowledgments}

We are grateful to Hal Mekeel (UNC) and Michelle Gignac (SMiF, Duke) for their expert technical assistance with electron microscopy sample preparation and data collection. We thank the staff at the Ramayamma International Eye Bank and surgeons at the L V Prasad Eye Institute (Hyderabad, India) for providing intact lenses from donors and nuclei from cataract patients. We thank North Carolina Eye Bank for providing transparent donor lenses. This work was presented in part at the 2010 International Congress of Eye Research (Montreal, Canada). This work was supported by NIH grants EY008148 (MJC) and EY005722 (Duke University core grant). 


\section{References}

Al-Ghoul KJ, Lane CW, Taylor VL, Fowler WC, Costello MJ. Distribution and type of morphological damage in human nuclear age-related cataracts. Exp Eye Res. 1996; 62:237-251. [PubMed: 8690033]

Asomugha CO, Gupta R, Srivastava OP. Identification of crystallin modifications in the human lens cortex and nucleus using laser capture microdis-section and CyDye labeling. Mol Vis. 2010; 16:476-494. [PubMed: 20352024]

Benedek GB. Theory of transparency of the eye. Appl Opt. 1971; 10:459-473. [PubMed: 20094474]

Benedek GB. Cataract as a protein condensation disease: the Proctor Lecture. Invest Ophthalmol Vis Sci. 1997; 38:1911-1921. [PubMed: 9331254]

Burette AC, Lesperance T, Crum J, Martone M, Volkmann N, Ellisman MH, Weinberg RJ. Electron tomographic analysis of synaptic ultrastructure. J Comp Neurol. 2012; 15:2697-2711. [PubMed: 22684938]

Chylack LT Jr, Lee MR, Tung WH, Cheng HM. Classification of human senile cataractous changes by the American Cooperative Cataract Research Group (CCRG) method. I Instrumentation and technique. Invest Ophthalmol Vis Sci. 1983; 24:424-431. [PubMed: 6832915]

Costello, MJ.; Kuszak, JR. The types, morphology and causes of cataracts. In: Klintworth, GK.; Garner, A., editors. Pathobiology of Ocular Disease. Informa Healthcare; New York: 2008. p. 469-494.

Costello MJ, McIntosh TJ, Robertson JD. Distribution of gap junctions and square array junctions in the mammalian lens. Invest Ophthalmol Vis Sci. 1989; 30:975-989. [PubMed: 2722452]

Costello MJ, Johnsen S, Gilliland KO, Freel CD, Fowler WC. Predicted light scattering from particles observed in human age-related nuclear cataracts using mie scattering theory. Invest Ophthalmol Vis Sci. 2007; 48:303-312. [PubMed: 17197547]

Costello MJ, Johnsen S, Metlapally S, Gilliland KO, Ramamurthy B, Krishna PV, Balasubramanian D. Ultrastructural analysis of damage to nuclear fiber cell membranes in advanced age-related cataracts from India. Exp Eye Res. 2008; 87:147-158. [PubMed: 18617164]

Costello MJ, Johnsen S, Metlapally S, Gilliland KO, Frame L, Balasubramanian D. Multilamellar spherical particles as potential sources of excessive light scattering in human age-related nuclear cataracts. Exp Eye Res. 2010; 91:881-889. [PubMed: 20888812]

Costello MJ. Cryo-electron microscopy of biological samples. Ultrastruct Pathol. 2006; 30:361-371. [PubMed: 17090515]

Erickson HP. Size and shape of protein molecules at the nanometer level determined by sedimentation, gel filtration, and electron microscopy. Biol Proced Online. 2009; 11:32-51. [PubMed: 19495910]

FitzGerald PG. Lens intermediate filaments. Exp Eye Res. 2009; 88:165-172. [PubMed: 19071112]

Freel CD, Gilliland KO, Wesley Lane C, Giblin FJ, Costello MJ. Fourier analysis of cytoplasmic texture in nuclear fiber cells from transparent and cataractous human and animal lenses. Exp Eye Res. 2002; 74:689-702. [PubMed: 12126943]

Frey TG, Perkins GA, Ellisman MH. Electron tomography of membrane-bound cellular organelles. Annu Rev Biophys Biomol Struct. 2006; 35:199-224. [PubMed: 16689634]

Gilliland KO, Freel CD, Lane CW, Fowler WC, Costello MJ. Multilamellar bodies as potential scattering particles in human age-related nuclear cataracts. Mol Vis. 2001; 7:120-130. [PubMed: 11435998]

Gilliland KO, Freel CD, Johnsen S, Fowler WC, Costello MJ. Distribution, spherical structure and predicted mie scattering of multi-lamellar bodies in human age-related nuclear cataracts. Exp Eye Res. 2004; 79:563-576. [PubMed: 15381040]

Gilliland KO, Johnsen S, Metlapally S, Costello MJ, Ramamurthy B, Krishna PV, Balasubramanian D. Mie light scattering calculations for an Indian age-related nuclear cataract with a high density of multilamellar bodies. Mol Vis. 2008; 14:572-582. [PubMed: 18385793]

Graw J. Genetics of crystallins: cataract and beyond. Exp Eye Res. 2009; 88:173-189. [PubMed: 19007775]

Exp Eye Res. Author manuscript; available in PMC 2013 August 01. 
Grey AC, Schey KL. Age-related changes in the spatial distribution of human lens alpha-crystallin products by MALDI imaging mass spectrometry. Invest Ophthalmol Vis Sci. 2009; 50:4319-4329. [PubMed: 19387068]

Haley DA, Horwitz J, Stewart PL. The small heat-shock protein, alphaB-crystallin, has a variable quaternary structure. J Mol Biol. 1998; 277:27-35. [PubMed: 9514758]

Haley DA, Bova MP, Huang QL, McHaourab HS, Stewart PL. Small heat-shock protein structures reveal a continuum from symmetric to variable assemblies. J Mol Biol. 2000; 298:261-272. [PubMed: 10764595]

Horwitz J. Alpha-crystallin can function as a molecular chaperone. Proc Natl Acad Sci U S A. 1992; 89:10449-10453. [PubMed: 1438232]

Horwitz J. Alpha-crystallin. Exp Eye Res. 2003; 76:145-153. [PubMed: 12565801]

Horwitz J. Alpha crystallin: the quest for a homogeneous quaternary structure. Exp Eye Res. 2009; 88:190-194. [PubMed: 18703051]

Jedziniak JA, Kinoshita JH, Yates EM, Hocker LO, Benedek GB. On the presence and mechanism of formation of heavy molecular weight aggregates in human normal and cataractous lenses. Exp Eye Res. 1973; 15:185-192. [PubMed: 4692231]

Jedziniak JA, Kinoshita JH, Yates EM, Benedek GB. The concentration and localization of heavy molecular weight aggregates in aging normal and cataractous human lenses. Exp Eye Res. 1975; 20:367-369. [PubMed: 1126401]

Koretz JF, Augusteyn RC. Electron microscopy of native and reconstituted alpha crystallin aggregates. Curr Eye Res. 1988; 7:25-30. [PubMed: 3359802]

Kramps HA, Stols AL, Hoenders HJ. On the quaternary structure of high-molecular-weight proteins from the bovine eye lens. Eur J Biochem. 1975; 50:503-509. [PubMed: 1112267]

Kremer JR, Mastronarde DN, McIntosh JR. Computer visualization of three-dimensional image data using IMOD. J Struct Biol. 1996; 116:71-76. [PubMed: 8742726]

Lampi KJ, Ma Z, Hanson SR, Azuma M, Shih M, Shearer TR, Smith DL, Smith JB, David LL. Agerelated changes in human lens crystallins identified by two-dimensional electrophoresis and mass spectrometry. Exp Eye Res. 1998; 67:31-43. [PubMed: 9702176]

Metlapally S, Costello MJ, Gilliland KO, Ramamurthy B, Krishna PV, Balasubramanian D, Johnsen S. Analysis of nuclear fiber cell cytoplasmic texture in advanced cataractous lenses from Indian subjects using Debye-Bueche theory. Exp Eye Res. 2008; 86:434-444. [PubMed: 18191834]

Michael R, Bron AJ. The ageing lens and cataract: a model of normal and pathological ageing. Philos Trans R Soc Lond B Biol Sci. 2011; 366:1278-1292. [PubMed: 21402586]

Peschek J, Braun N, Franzmann TM, Georgalis Y, Haslbeck M, Weinkauf S, Buchner J. The eye lens chaperone alpha-crystallin forms defined globular assemblies. Proc Natl Acad Sci U S A. 2009; 106:13272-13277. [PubMed: 19651604]

Rao PV, Huang QL, Horwitz J, Zigler JS Jr. Evidence that alpha-crystallin prevents non-specific protein aggregation in the intact eye lens. Biochim Biophys Acta. 1995; 1245:439-447. [PubMed: 8541324]

Sandilands A, Prescott AR, Carter JM, Hutcheson AM, Quinlan RA, Richards J, FitzGerald PG. Vimentin and CP49/filensin form distinct networks in the lens which are independently modulated during lens fibre cell differentiation. J Cell Sci. 1995; 108 (Pt 4):1397-1406. [PubMed: 7615661]

Schietroma C, Fain N, Zampighi LM, Lanzavecchia S, Zampighi GA. The structure of the cytoplasm of lens fibers as determined by conical tomography. Exp Eye Res. 2009; 88:566-574. [PubMed: 19103200]

Sharma KK, Santhoshkumar P. Lens aging: effects of crystallins. Biochim Biophys Acta. 2009; 1790:1095-1108. [PubMed: 19463898]

Sosinsky GE, Crum J, Jones YZ, Lanman J, Smarr B, Terada M, Martone ME, Deerinck TJ, Johnson JE, Ellisman MH. The combination of chemical fixation procedures with high pressure freezing and freeze substitution preserves highly labile tissue ultrastructure for electron tomography applications. J Struct Biol. 2008; 161:359-371. [PubMed: 17962040]

Spector A, Li S, Sigelman J. Age-dependent changes in the molecular size of human lens proteins and their relationship to light scatter. Invest Ophthalmol. 1974; 13:795-798. [PubMed: 4411898] 
Su S, Liu P, Zhang H, Li Z, Song Z, Zhang L, Chen S. Proteomic analysis of human age-related nuclear cataracts and normal lens nuclei. Invest Ophthalmol Vis Sci. 2011; 52:4182-4191. [PubMed: 21436267]

Taylor VL, Costello MJ. Fourier analysis of textural variations in human normal and cataractous lens nuclear fiber cell cytoplasm. Exp Eye Res. 1999; 69:163-174. [PubMed: 10433853]

Taylor VL, al-Ghoul KJ, Lane CW, Davis VA, Kuszak JR, Costello MJ. Morphology of the normal human lens. Invest Ophthalmol Vis Sci. 1996; 37:1396-1410. [PubMed: 8641842]

Vanhecke D, Asano S, Kochovski Z, Fernandez-Busnadiego R, Schrod N, Baumeister W, Lucic V. Cryo-electron tomography: methodology, developments and biological applications. J Microsc. 2011; 242:221-227. [PubMed: 21175615]

Vrensen G, Willekens B. Classification and prevalence of early senile lens opacities in human donor eyes. Dev Ophthalmol. 1989; 17:181-187. [PubMed: 2792520]

Wang Z, Obidike JE, Schey KL. Posttranslational modifications of the bovine lens beaded filament proteins filensin and CP49. Invest Ophthalmol Vis Sci. 2010; 51:1565-1574. [PubMed: 19875662]

Zampighi GA, Zampighi LM, Fain N, Lanzavecchia S, Simon SA, Wright EM. Conical electron tomography of a chemical synapse: vesicles docked to the active zone are hemi-fused. Biophys J. 2006; 91:2910-2918. [PubMed: 16877508]

Zampighi GA, Zampighi L, Lanzavecchia S. The three-dimensional distribution of alphaA-crystalline in rat lenses and its possible relation to transparency. PLoS One. 2011; 6:e23753. [PubMed: 21909355]

Zhou Z, Wang B, Luo Y, Zhou G, Hu S, Zhang H, Ma X, Qi Y. Major intrinsic protein (MIP) polymorphism is associated with age-related cataract in Chinese. Mol Vis. 2011; 17:2292-2296. [PubMed: 21921980] 

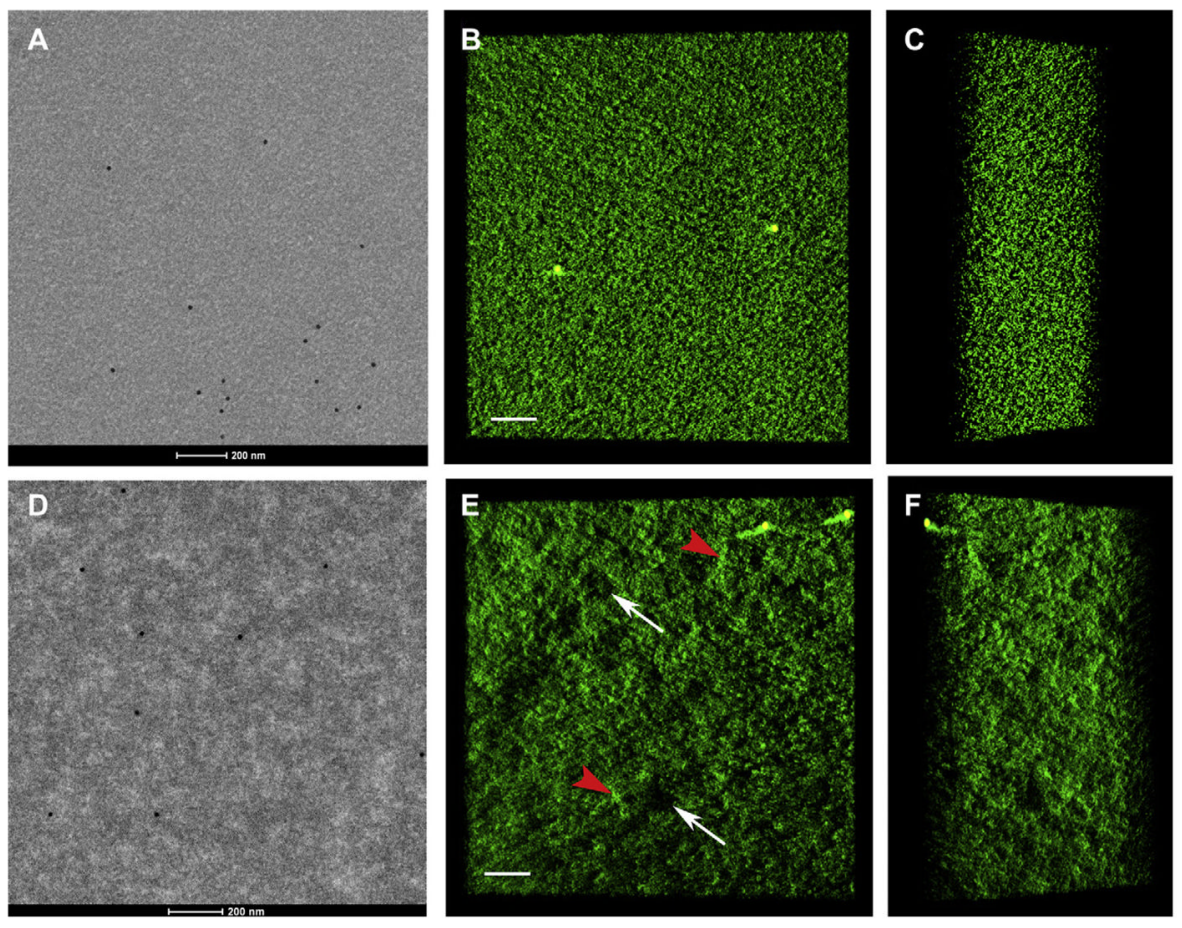

Fig. 1.

Cytoplasmic texture in donor and cataractous nuclear fiber cells. A: Conventional electron micrograph from a human transparent nucleus (Indian donor, 56 years; grade 0 on a 0-4 scale). B: and C: Selected images at different tilts from the tomographic reconstruction. D: Conventional electron micrograph from an advanced nuclear cataract (Indian, 48 years; grade 4 on a $0-4$ scale). E: and F: Selected images of the tomographic reconstruction at different tilts. The packing of cytoplasmic protein in the transparent donor lens is relatively smooth, homogeneous and dense showing uniform texturing $(\mathrm{A}-\mathrm{C})$ with fluctuations roughly $20-50 \mathrm{~nm}$, whereas the packing in the nuclear cataract is heterogeneous (D-F) with irregular regions of high density (E: red arrowheads) and low density (E: white arrows) some of which are about 100-200 nm across. Several $15 \mathrm{~nm}$ gold particles appear as black dots in the electron micrographs and as light spots in the inverse contrast reconstructions. Bars are $200 \mathrm{~nm}(\mathrm{~A}, \mathrm{D})$ and $100 \mathrm{~nm}(\mathrm{~B}, \mathrm{E})$. 


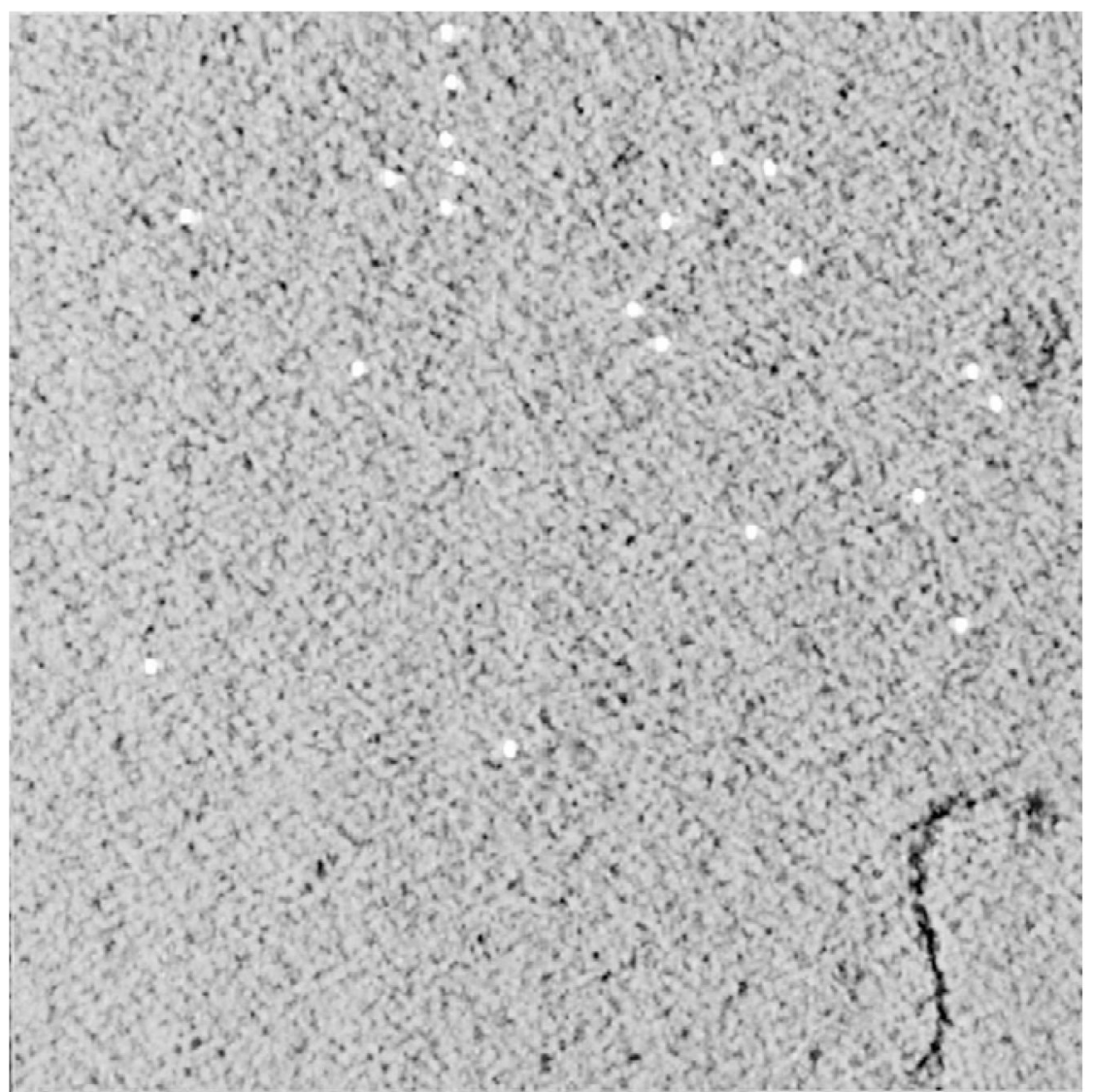

Fig. 2.

Still image from a video animation of a tomographic reconstruction for a transparent donor lens. Width is $1600 \mathrm{~nm}$. 


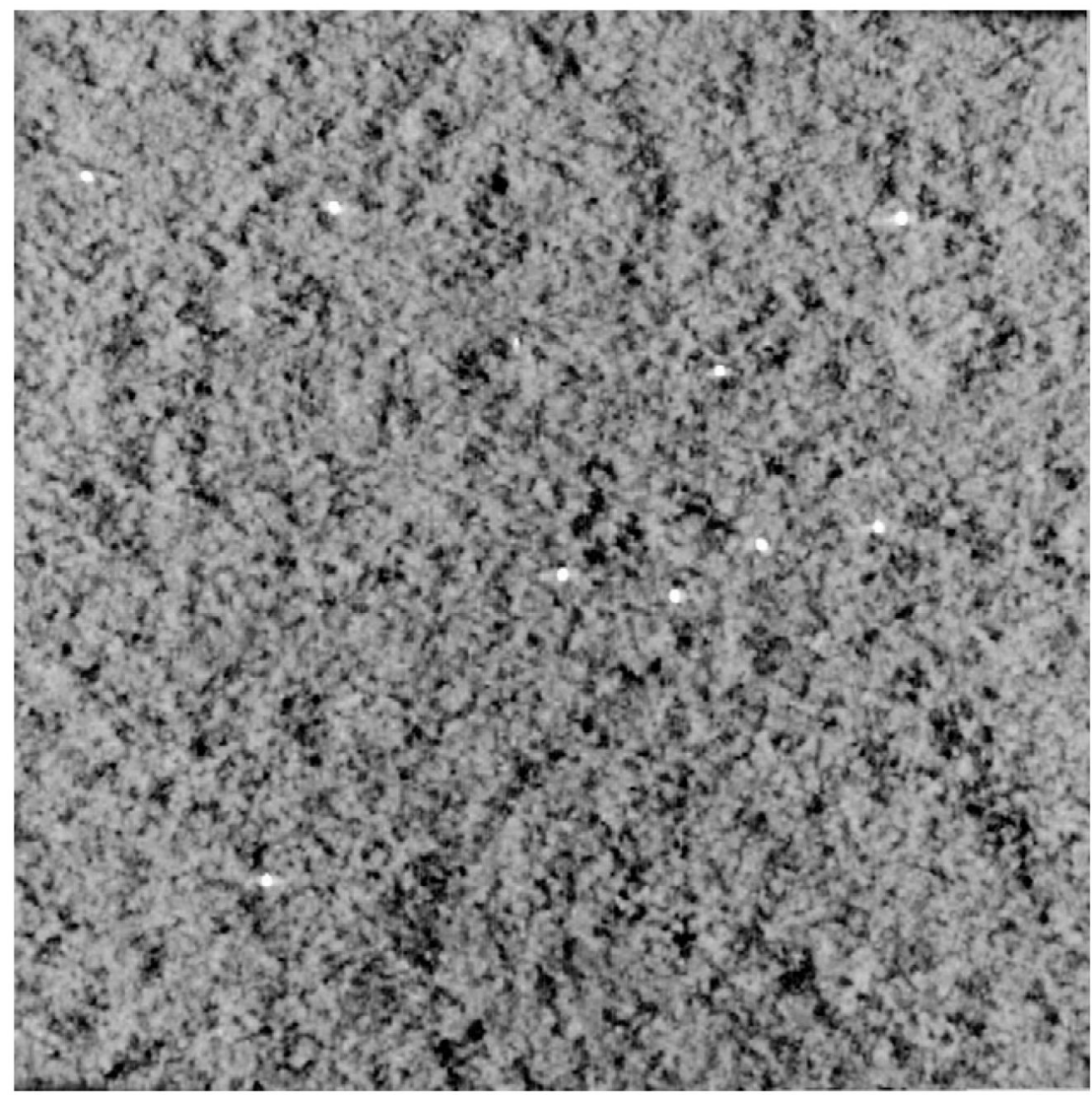

Fig. 3.

Still image from a video animation of a tomographic reconstruction for an advanced nuclear cataract. Width is $1600 \mathrm{~nm}$. 

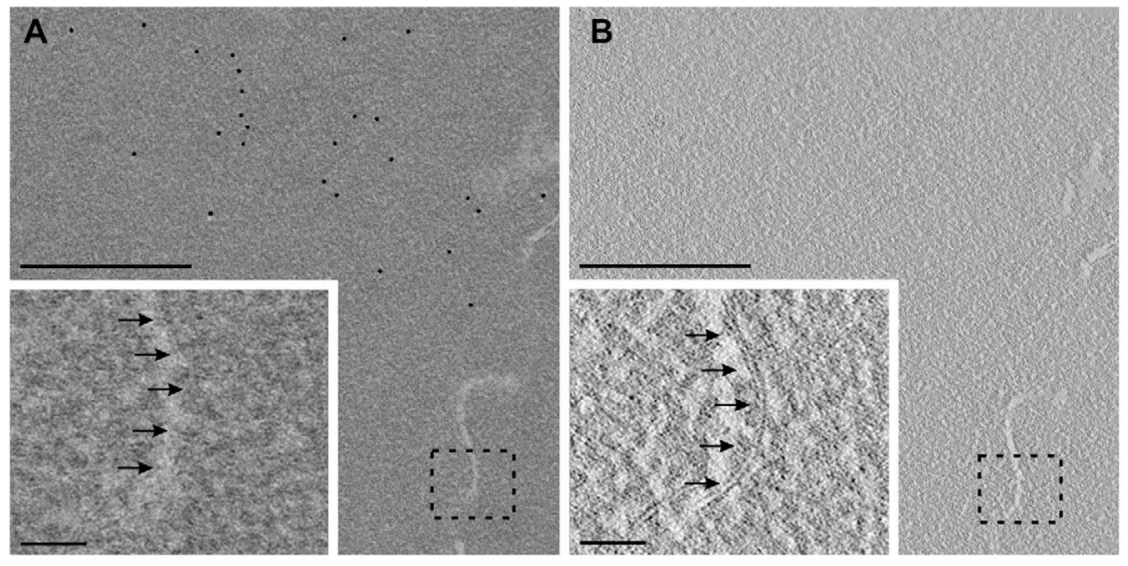

Fig. 4.

Plasma membrane ultrastructure in the transparent donor nucleus (Indian, 56 years). A: Conventional electron micrograph showing a curved membrane (that appears electron lucent at low magnification) and the trilamellar profile barely visible at high magnification (inset, arrows). The black dots are $15 \mathrm{~nm}$ gold particles. B: The same curved membrane in A seen in the tomographic reconstruction. A thin slice at the proper orientation is used to reveal the trilamellar profile in great clarity (inset, arrows). The $7 \mathrm{~nm}$ thick membrane and deposits on the membrane (second and third arrows from bottom) are easily resolved. Gold particles were selectively removed during the reconstruction. Bars $500 \mathrm{~nm}$ overview (A, B) and 50 $\mathrm{nm}$ in insets (A, B). 

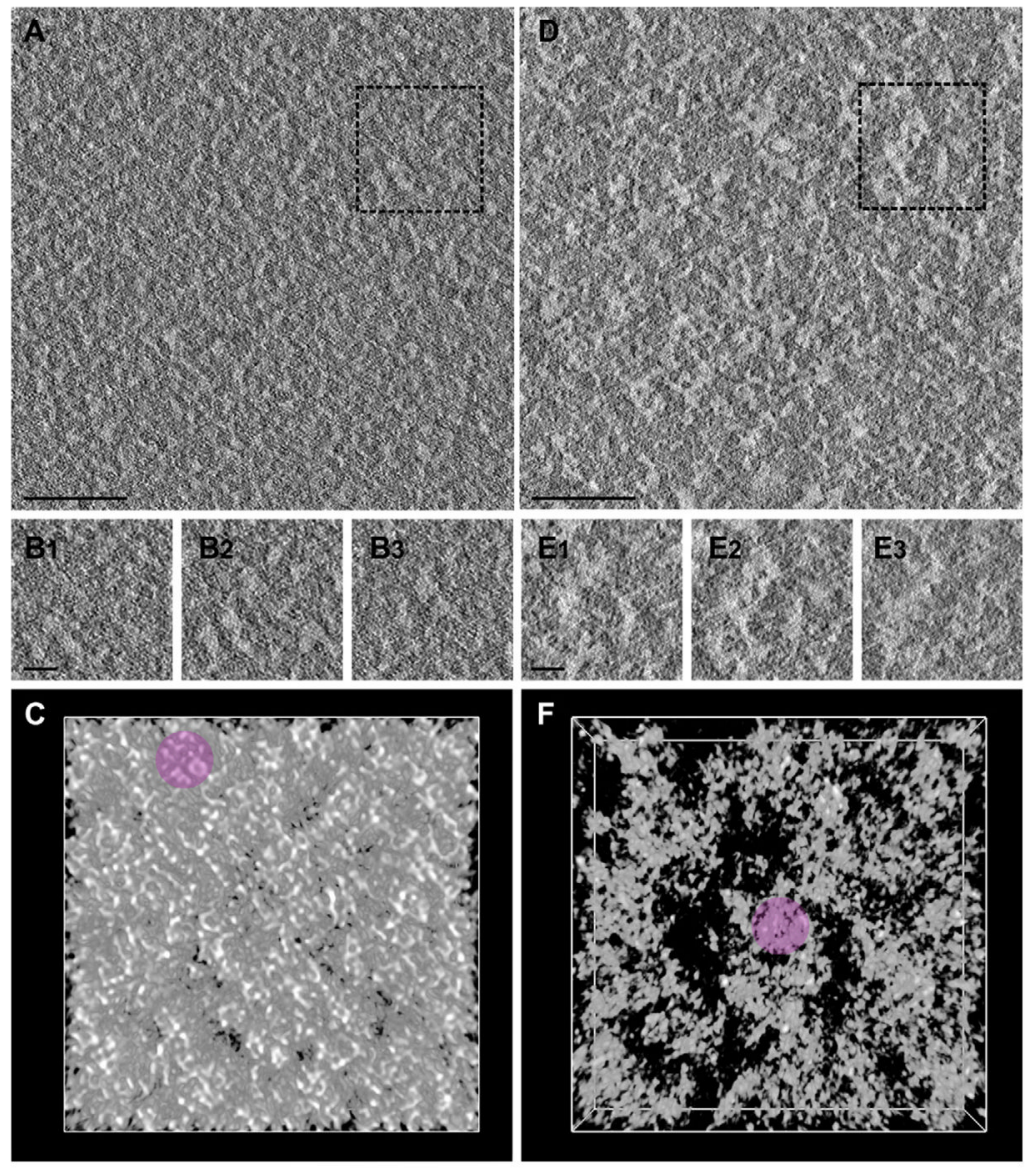

Fig. 5.

Detailed comparison of cytoplasmic texture in reconstructions from donor and cataractous nuclei. A: Overview of a selected region of cytoplasm in the reconstruction of the transparent donor nucleus (Indian, 56 years). B: Different levels $\left(\mathrm{B}_{1}-\mathrm{B}_{3}\right)$ along the $z$-axis at the boxed region in (A). Note the minimal density fluctuations at each level. C: Zero tilt view of the reconstruction at the boxed region in (A). Note that the scale of cytoplasmic density fluctuations is typically less than $50 \mathrm{~nm}$. A $16 \mathrm{~nm}$ circle (upper left) over a cluster of high density globules would correspond to the profile of an alpha-crystallin sphere but no such correspondence is seen here or in the remainder of the image. D: Overview of a representative region of cytoplasm from the advanced nuclear cataract (Indian, 48 years). E: Different levels $\left(\mathrm{E}_{1}-\mathrm{E}_{3}\right)$ along the $z$-axis at the boxed region in (D). Note the wide variation in densities. F: Zero tilt view of the reconstruction at the boxed region in (D). Regions of particle clustering and wide density fluctuations are obvious with some in the $50-100 \mathrm{~nm}$ range. A $16 \mathrm{~nm}$ circle (center) surrounds a cluster of globules but does not circumscribe a recognizable substructural unit or distinguish the cluster from adjacent irregular clusters. Moreover, large low-density regions of irregular size and shape are present enhancing fluctuations in density. Bars $100 \mathrm{~nm}$ (A, B) and $25 \mathrm{~nm}$ (B, E). Zero tilt views are $120 \mathrm{~nm}$ on an edge $(\mathrm{C}, \mathrm{F})$. 


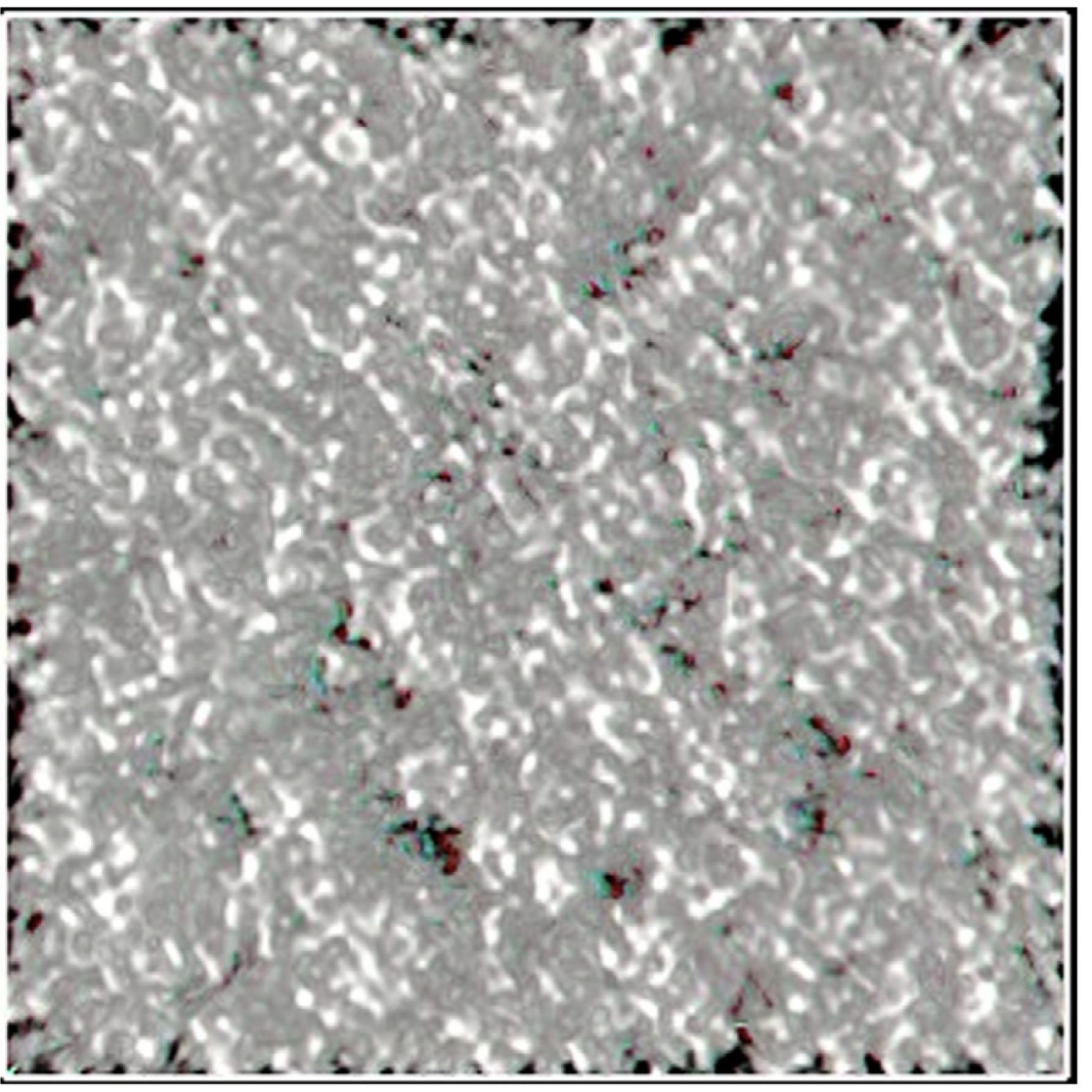

Fig. 6.

Anaglyph stereo video animation of a transparent donor lens. Width is $120 \mathrm{~nm}$. 


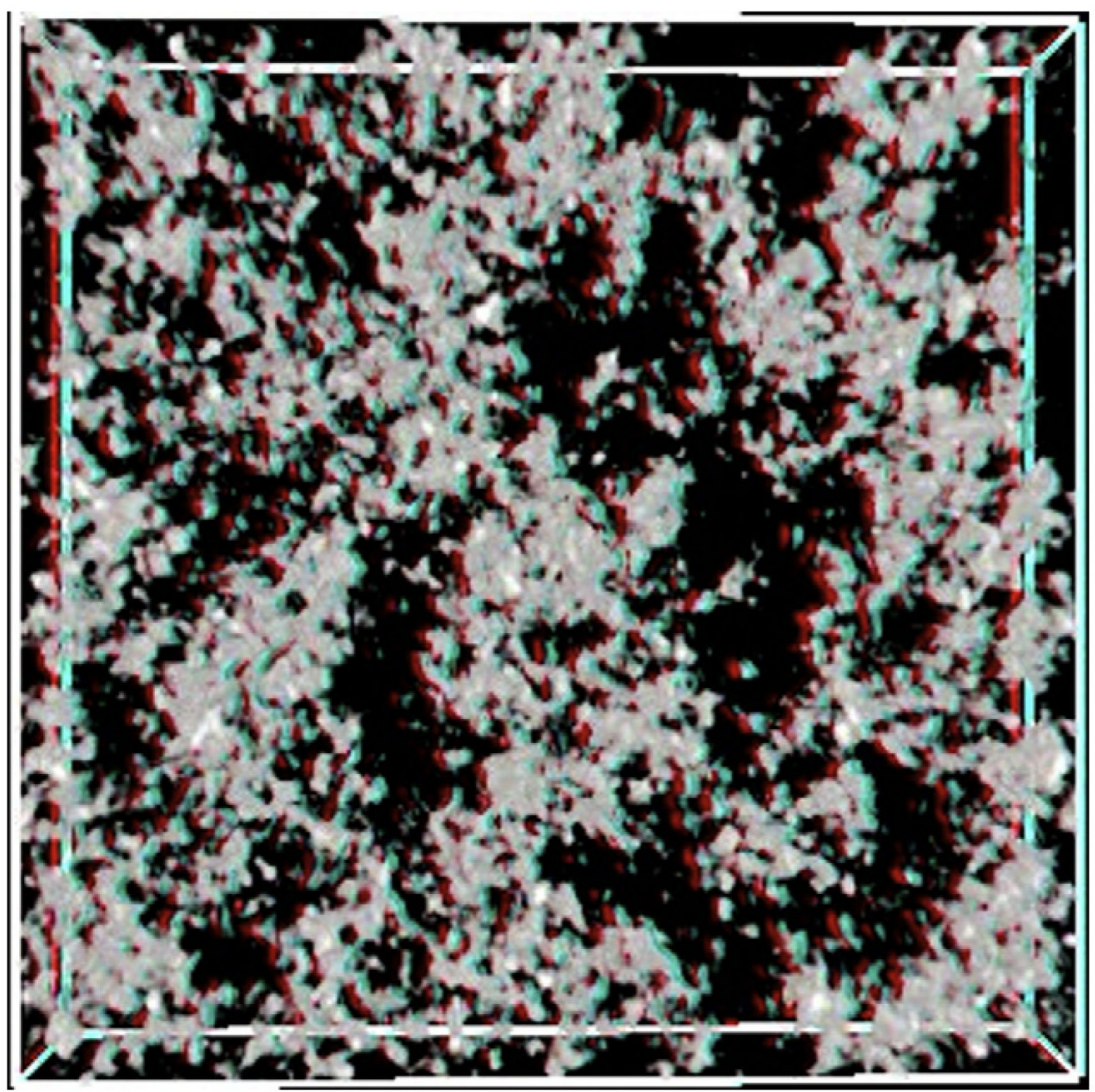

Fig. 7.

Anaglyph stereo video animation of an advanced nuclear cataract. Width is $120 \mathrm{~nm}$. 

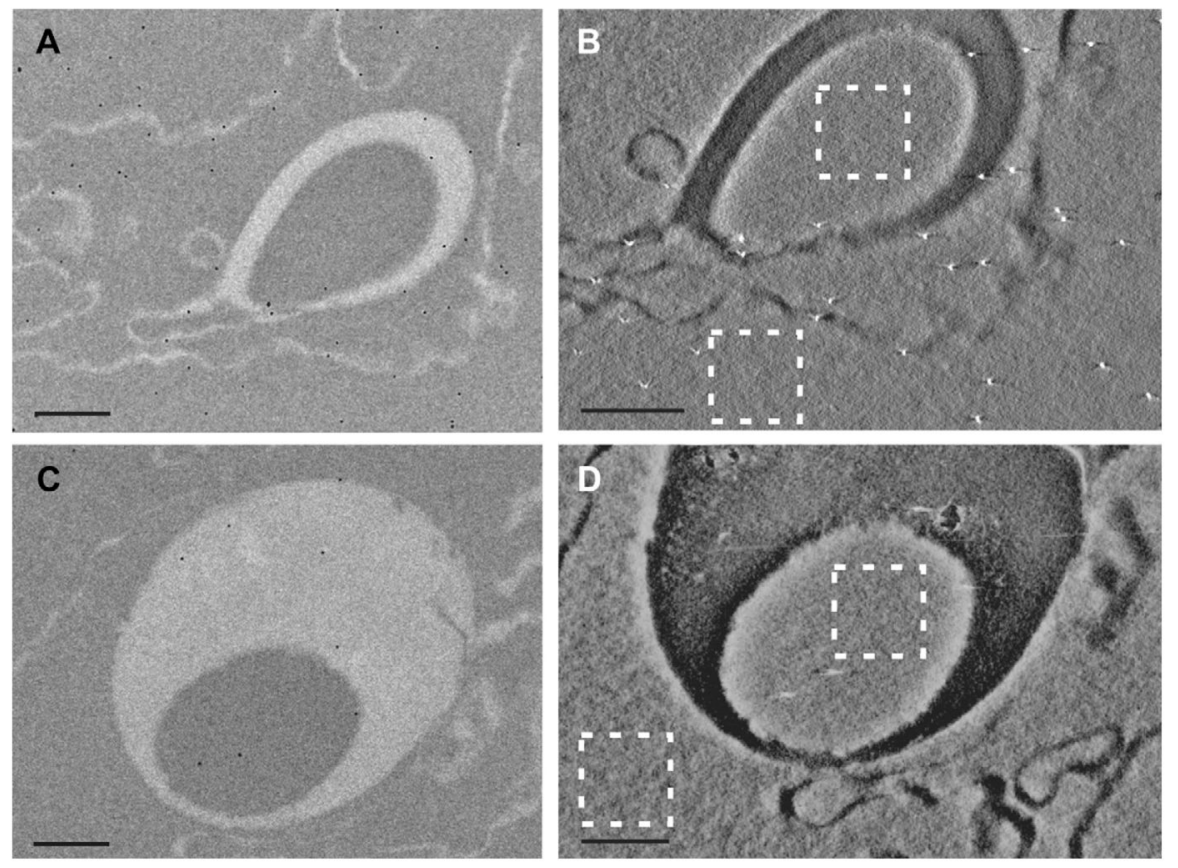

Fig. 8.

Multilamellar bodies from an early stage nuclear cataract. A: Conventional electron micrograph of an MLB core surrounded by a well-defined electron lucent rim and typical cytoplasm from an age-related nuclear cataract (US cataract, 85 years; grade 2 on a $0-4$ scale). B: Zero tilt view of the tomographic reconstruction showing similar texture of the adjacent cytoplasm (outer boxed region) compared to the core (central boxed region). C: Conventional electron micrograph of a mature MLB with a dense core and very large electron lucent rim (US cataract, 85 years; grade 2 on a $0-4$ scale). D: Zero tilt view of the reconstruction showing typical textured cytoplasm adjacent to the MLB (outer boxed region) similar to or slightly more textured than the core of the MLB (central boxed region). In this reverse contrast image, the rim is dark and has very low mass density (epon embedding media) even though the contrast has been adjusted to bring up structural features only faintly visible in the standard TEM image in $8 \mathrm{C}$. Black and white dots are $15 \mathrm{~nm}$ gold fiducial markers. Scale bars are $500 \mathrm{~nm}$. 


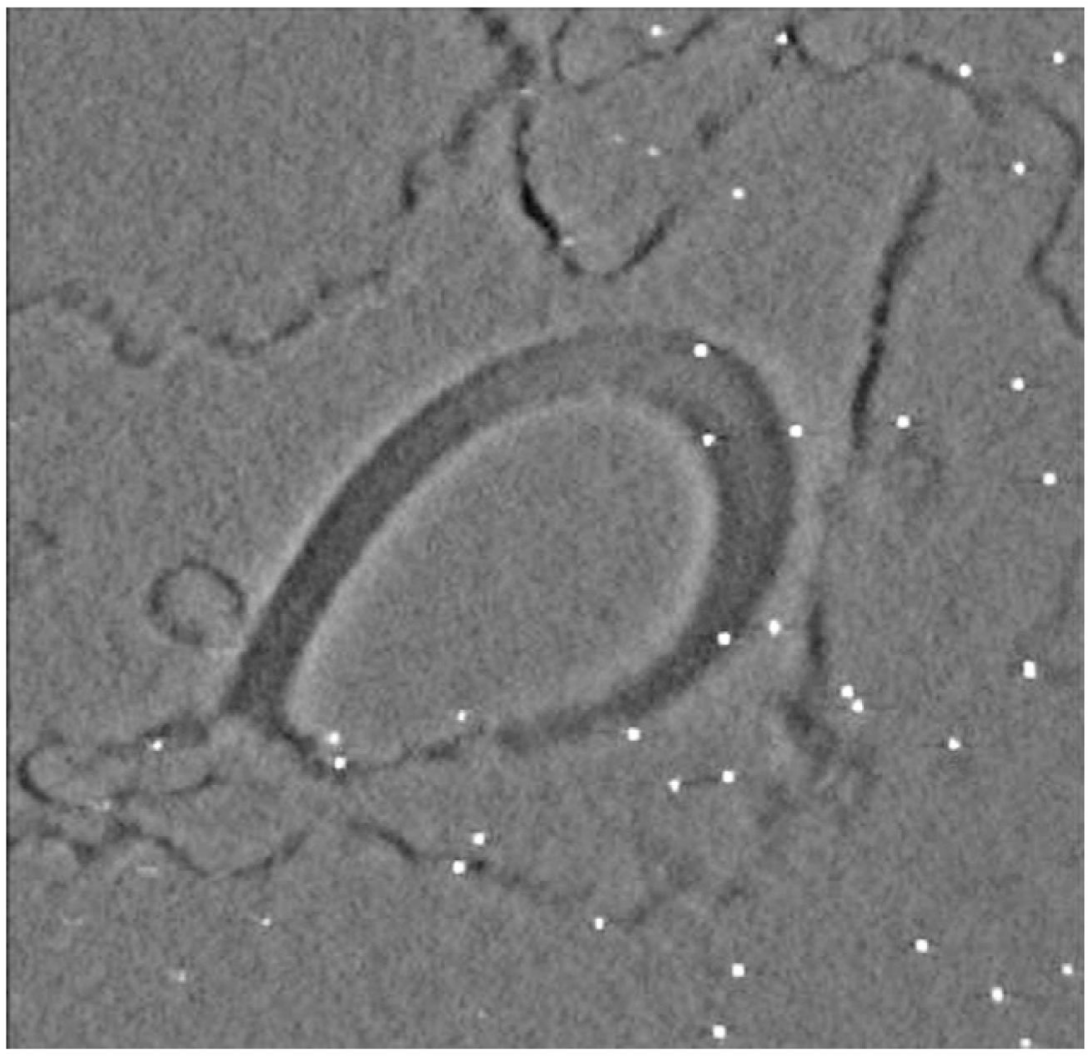

Fig. 9.

Video animation of an MLB from a US nuclear cataract. Width is $3300 \mathrm{~nm}$. 


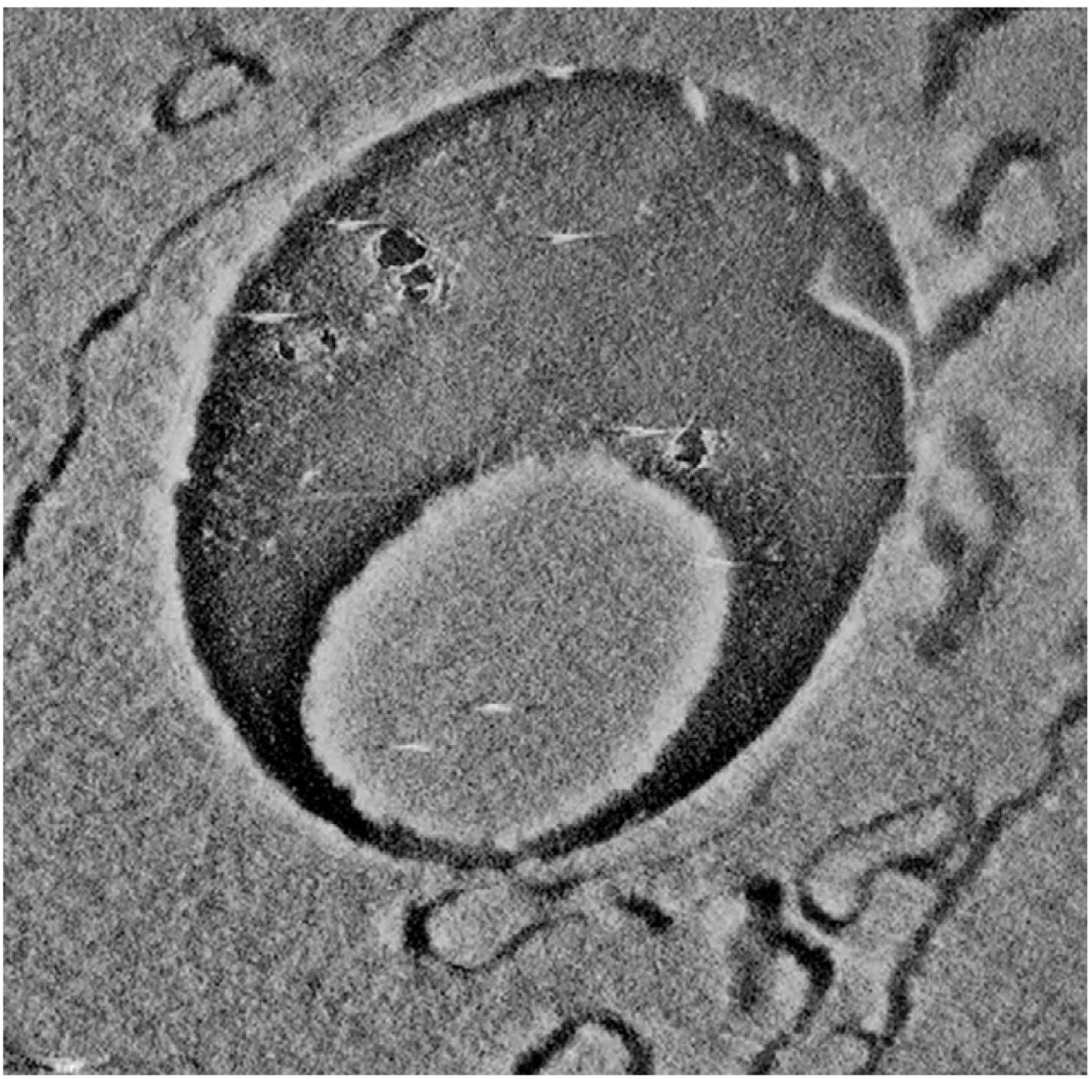

Fig. 10.

Video animation of an MLB from a US nuclear cataract with a dense core and wide clear rim. Width is $3500 \mathrm{~nm}$. 